\title{
THICKNESS DEBIT IN CREEP PROPERTIES OF PWA 1484
}

\author{
V. Seetharaman and A. D. Cetel
}

Pratt \& Whitney, 400 Main Street, East Hartford, CT 06108

Keywords: Single crystals, creep rupture, deformation constraints

\begin{abstract}
The effect of section thickness on the creep properties of a single crystal superalloy, PWA 1484 was investigated. For this purpose, a series of isothermal, constant load creep tests were conducted on uncoated sheet specimens in air at temperatures ranging from $760^{\circ} \mathrm{C}$ to $982^{\circ} \mathrm{C}$ and at stresses varying from $207 \mathrm{MPa}$ to 758 $\mathrm{MPa}$. The average time to reach $1 \%$ creep strain showed very weak dependence on specimen thickness at all test conditions. In contrast, the thickness debit associated with rupture life showed a complex dependence on test conditions. For example, creep rupture lives obtained at $760^{\circ} \mathrm{C}$ and $758 \mathrm{MPa}$ decreased sharply $(60 \%)$ with a reduction in specimen thickness from $3.18 \mathrm{~mm}$ to $0.38 \mathrm{~mm}$. However, rupture lives of specimens tested at $871^{\circ} \mathrm{C}$ and $982^{\circ} \mathrm{C}$ exhibited a relatively modest dependence on specimen thickness. The results have been interpreted qualitatively in terms of the effect of plastic constraint on the deformation and fracture of ligaments between the interdendritic creep voids created during creep deformation.
\end{abstract}

\section{Introduction}

The effect of section thickness (thickness debit) on creep deformation and rupture properties of superalloy castings plays an important role in the design and durability analysis of turbine airfoils [1-10]. Past experience with conventionally cast (CC) superalloys suggests a substantial ( $\sim$ five fold) reduction in the rupture life of thin wall castings compared with bulk castings. The magnitude of the thin wall debit is reduced in the directionally solidified, columnar-grain castings (CG) and is smallest for single crystal (SC) alloys. A qualitative comparison of the thickness debit in $\mathrm{CC}, \mathrm{CG}$, and $\mathrm{SC}$ alloys is provided in Figure 1 [1]. There are several possible explanations for the thickness debit observed in thin wall castings. They fall into the following categories:

(1) Fracture: Intergranular creep fracture occurs in equiaxed alloys as a result of cavity nucleation, growth, and coalescence along grain boundaries. Under these conditions, the effect on load carrying capability is greater in material with fewer grains per unit cross-sectional area where each grain represents a large fraction of the cross section [4].

(2) Oxygen embrittlement: Stress-assisted diffusion of oxygen along the grain boundaries causes embrittlement (lowers rupture ductility and, in general, rupture life). This mechanism becomes very important for uncoated specimens with very low section thickness [7-9].

(3) Deformation: These include (a) a change in the degree of constraint on plastic deformation with a change in the section thickness and (b) change in the importance of deformation anisotropy with section thickness (fewer grains across the specimen thickness or diameter).

While all three mechanisms may contribute to the thin wall debit in CC and CG alloys, the thickness debit in SC alloys is most likely caused by the differences in the deformation constraint and plastic anisotropy between thick and thin sections.

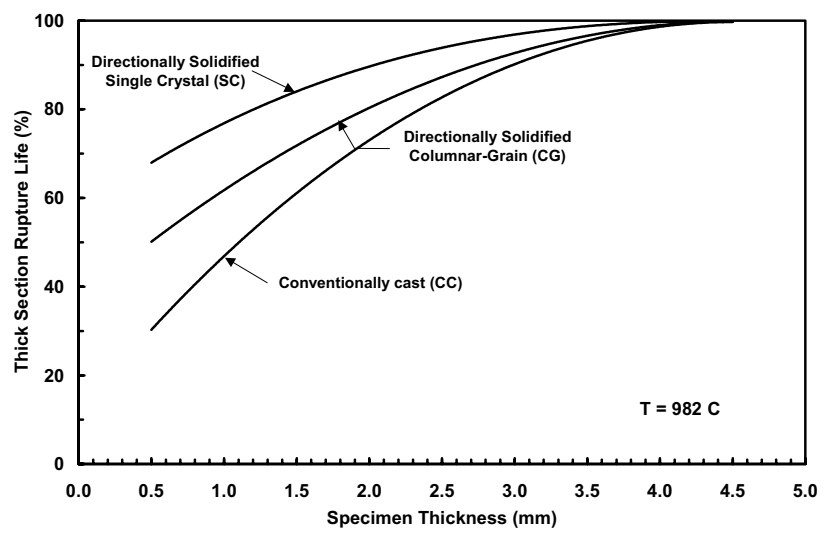

Figure 1 Comparison of the thickness debit data for conventionally cast (CC), columnar-grain (CG) and single crystal (SC) alloys at $982^{\circ} \mathrm{C}[1]$.

In recent years, the importance of the thickness debit has increased dramatically. This is because of increasingly complex cooling passages in advanced turbine blades that, in turn, require a significant reduction in the casting wall thickness. Woodford [8] has recently shown that the creep strength of CMSX-4 alloy measured at 0.5 to $1 \%$ strain levels is unaffected by section thickness. However, the fracture resistance of the alloy evaluated from smooth or notched tensile tests was strongly dependent on the section thickness. Doner and Heckler $[9,10]$ showed that the thickness debit in the stress rupture lives of uncoated CMSX-3 specimens was significant when the applied stress was below $275 \mathrm{MPa}(40 \mathrm{ksi})$. They also demonstrated that the rupture lives of coated specimens were essentially independent of section thickness suggesting that the observed thickness-debit was primarily due to environmental effects. In contrast, Soechting [11] reported a debit of $30-40 \%$ in creep rupture strength of coated PWA 1480 specimens when the section thickness was reduced from $1.52 \mathrm{~mm}$ (60 mils) to $0.25 \mathrm{~mm}(10 \mathrm{mils})$. Such conflicting results suggest that in spite of the large amount of research work on the creep properties of single crystal alloys, the nature and extent of thin wall debit are not well understood. 
The main objective of the current work was to establish the magnitude of the thin wall debit in the creep rupture properties of a second generation production single crystal alloy (PWA 1484). Towards this objective, creep tests were performed on specimens of PWA 1484 with varying section thicknesses, but identical chemical composition, crystal orientation, and microstructure. Because these specimens were machined from bulk single crystal castings, it was possible to eliminate the influence of other complicating factors such as variations in secondary dendrite arm spacing, micro-segregation patterns, micro-shrinkage, and porosity on the creep properties.

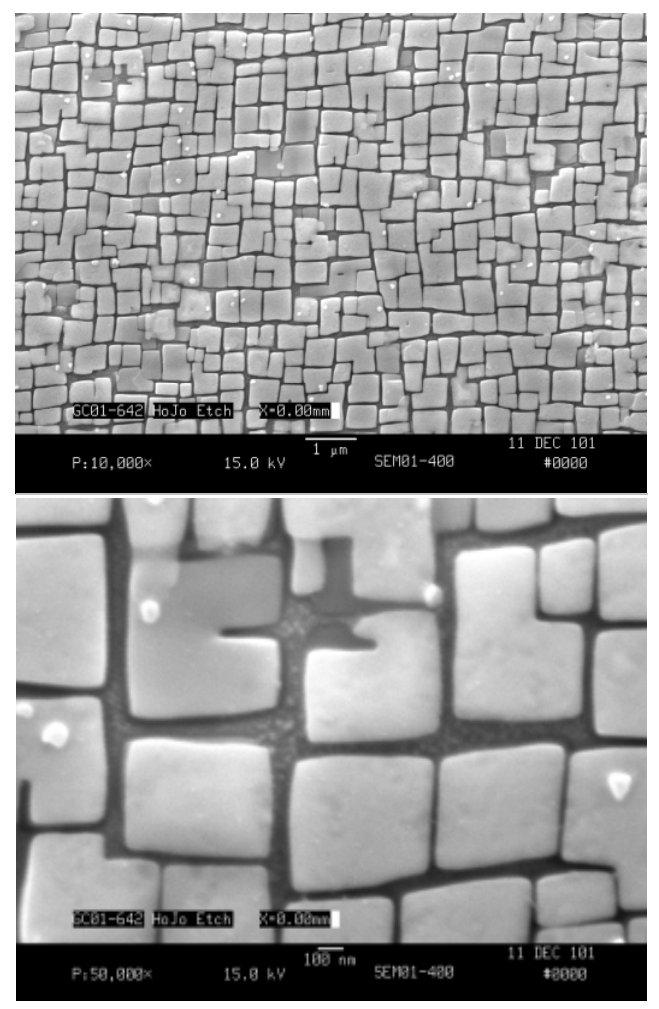

Figure 2 Microstructures of the fully heat treated PWA 1484 alloy showing coarse, blocky $\gamma^{\prime}$ precipitates as well as fine, spherical $\gamma^{\prime}$ precipitates within $\gamma$ channels.

\section{Experimental Procedures}

Rectangular bars (177.8 mm x $25.4 \mathrm{~mm} \times 19.1 \mathrm{~mm}$ ) of PWA 1484 $[12,13]$ cast at Pratt \& Whitney's in-house Rapid Prototype Casting Laboratory were used for this study. The nominal chemical composition of the alloy (in weight percent) was Co $10.0 \%$, Cr 5.0\%, Al 5.6\%, Ta 8.7\%, W 6.0\%, Mo 2.0\%, Re 3.0\%, and $\mathrm{Ni}$ the balance. X-ray diffraction (Laue) analysis and macroetching were used to confirm that the bars were indeed single crystals with primary orientation within $10^{\circ}$ of [100] axis. Because no seed crystals were used in the casting process, the bars had nearly random secondary orientations. The bars were subjected to a standard sequence of heat treatment cycles, viz., solution annealing at $1316^{\circ} \mathrm{C}\left(2400^{\circ} \mathrm{F}\right)$ for 2 hours in vacuum, coating diffusion heat treatment at $1080^{\circ} \mathrm{C}\left(1975^{\circ} \mathrm{F}\right)$ for 4 hours in a controlled atmosphere, and precipitation heat treatment at $704^{\circ} \mathrm{C}$ $\left(1300^{\circ} \mathrm{F}\right)$ for 24 hours in air. Figure 2 illustrates the typical microstructures of the heat-treated bars. The microstructure consisted of coarse, primary $\gamma^{\prime}$ precipitates $(\sim 0.45 \mu \mathrm{m})$ with a blocky morphology, together with a distribution of fine $(\sim 30 \mathrm{~nm})$, spherical $\gamma^{\prime}$ precipitates within the narrow $\gamma$ channels. These observations are in general agreement with previous studies on PWA 1484 [13].

Standard creep test specimens with cylindrical and rectangular cross-sections were electro-discharge machined from the heattreated bars and ground to remove the recast layer. The thickness of the sheet specimens was varied from $0.38 \mathrm{~mm}$ to $3.18 \mathrm{~mm}$ (15 mils to 125 mils). Moreover, the sheet specimens were machined such that the orientation of the specimen width was within \pm 2 degrees of $<100>$ (Figure 3).

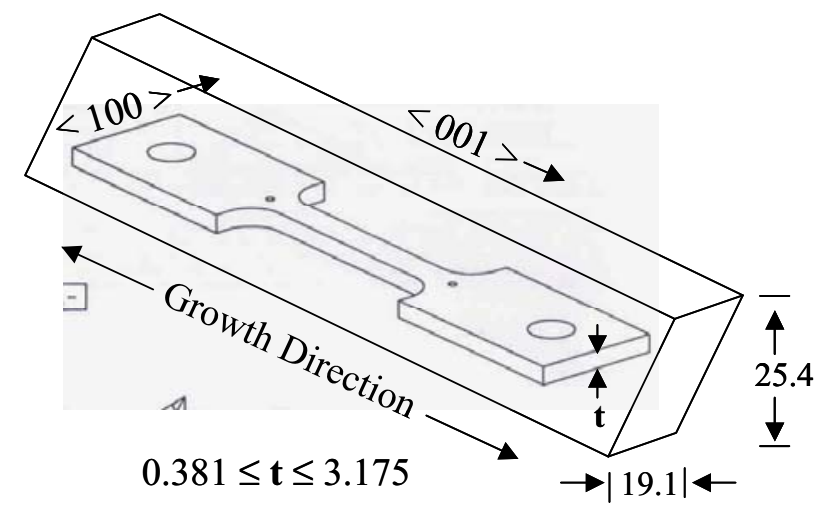

Figure 3 Schematic diagram of the sheet specimen used for creep testing and its orientation in the cast single crystal bar. All dimensions are in $\mathrm{mm}$.

Isothermal, constant load creep tests were conducted on uncoated specimens in air at four different conditions: $760^{\circ} \mathrm{C} / 758 \mathrm{MPa}$ $\left(1400^{\circ} \mathrm{F} / 110 \mathrm{ksi}\right), 871^{\circ} \mathrm{C} / 413 \mathrm{MPa}\left(1600^{\circ} \mathrm{F} / 60 \mathrm{ksi}\right), 982^{\circ} \mathrm{C} / 207 \mathrm{MPa}$ $\left(1800^{\circ} \mathrm{F} / 30 \mathrm{ksi}\right)$, and $982^{\circ} \mathrm{C} / 248 \mathrm{MPa}\left(1800^{\circ} \mathrm{F} / 36 \mathrm{ksi}\right)$. In addition, baseline creep tests were performed on cylindrical specimens (gage diameter $=3.18 \mathrm{~mm})$ at $760^{\circ} \mathrm{C} / 758 \mathrm{MPa}\left(1400^{\circ} \mathrm{F} / 110 \mathrm{ksi}\right)$ and $982^{\circ} \mathrm{C} / 248 \mathrm{MPa}\left(1800^{\circ} \mathrm{F} / 36 \mathrm{ksi}\right)$. Three specimens were tested for each condition in order to insure a modicum of statistical validity for the creep properties measured. Displacement vs. time data logged during the creep tests were converted into creep strain vs. time plots. Furthermore, creep data were analyzed in terms of the primary strain $\left(\varepsilon_{p}\right)$, the rupture strain $\left(\varepsilon_{r}\right)$, the rupture life $\left(t_{r}\right)$, as well as times required for attaining different strain values, e.g., $1 \%\left(t_{1 \%}\right)$. Microstructures and the fracture morphology of selected specimens after rupture were characterized by optical microscopy and scanning electron microscopy in order to understand and rationalize the creep behavior of different specimens.

\section{Results}

Table I. Baseline creep data obtained from bulk specimens of PWA 1484

\begin{tabular}{|l|l|l|l|l|}
\hline $\begin{array}{l}\mathrm{T} \\
(\mathrm{C})\end{array}$ & $\begin{array}{l}\sigma \\
\text { MPa }\end{array}$ & $\begin{array}{l}\mathrm{t}_{1 \%} \\
\text { (hours) }\end{array}$ & $\begin{array}{l}\mathrm{t}_{\mathrm{r}} \\
\text { (hours) }\end{array}$ & $\begin{array}{l}\varepsilon_{\mathrm{r}} \\
(\mathbf{\%})\end{array}$ \\
\hline 760 & 758 & 1.8 & 729 & 16.4 \\
\hline 982 & 248 & 102 & 218 & 26.6 \\
\hline
\end{tabular}

Baseline creep data listed in Table I were obtained by testing 
cylindrical specimens at $760^{\circ} \mathrm{C} / 758 \mathrm{MPa}\left(1400^{\circ} \mathrm{F} / 110 \mathrm{ksi}\right)$ and $982^{\circ} \mathrm{C} / 248 \mathrm{MPa}\left(1800^{\circ} \mathrm{F} / 36 \mathrm{ksi}\right)$. Typical creep curves corresponding to these test conditions are shown in Figure 4. These conditions represent two extremes of the deformation behavior, i.e., the ratios of the applied stress to the yield strength $\left(\sigma / \sigma_{\mathrm{y}}\right)$ for PWA 1484 at $760^{\circ} \mathrm{C} / 758 \mathrm{MPa}\left(1400^{\circ} \mathrm{F} / 110 \mathrm{ksi}\right)$ and $982^{\circ} \mathrm{C} / 248 \mathrm{MPa}\left(1800^{\circ} \mathrm{F} / 36 \mathrm{ksi}\right)$ are 0.79 and 0.46 , respectively. Secondly, the creep curve obtained at $760^{\circ} \mathrm{C} / 758 \mathrm{MPa}$ $\left(1400^{\circ} \mathrm{F} / 110 \mathrm{ksi}\right)$ exhibits a strong primary creep component: Primary creep accounts for approximately $6 \%$ strain. In contrast, primary creep is negligible in tests performed at $982^{\circ} \mathrm{C} / 248 \mathrm{MPa}$ $\left(1800^{\circ} \mathrm{F} / 36 \mathrm{ksi}\right)$. Furthermore, the former condition results in steady state creep observed over much of the creep test and a relatively short tertiary creep regime. On the other hand, creep curves obtained at $982^{\circ} \mathrm{C} / 248 \mathrm{MPa}\left(1800^{\circ} \mathrm{F} / 36 \mathrm{ksi}\right)$ show no steady state creep at all; instead, the tertiary stage involving a continuous increase in the creep rate represents the major portion of the creep curve. It is important to note that the creep deformation at $760^{\circ} \mathrm{C}\left(1400^{\circ} \mathrm{F}\right)$ is mainly controlled by thermally activated cross slip of dislocation segments from octahedral-tocube planes, while the rate controlling mechanism for creep deformation at $982^{\circ} \mathrm{C}\left(1800^{\circ} \mathrm{F}\right)$ is dislocation climb over $\gamma^{\prime}$ precipitates [1, 5-7, 11-15].

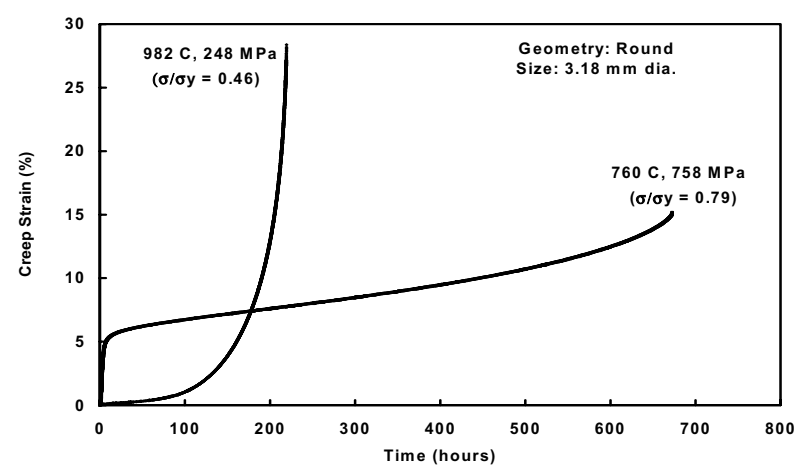

Figure 4 Typical creep curves obtained from cylindrical specimens tested at $760^{\circ} \mathrm{C}$ and $982^{\circ} \mathrm{C}$.

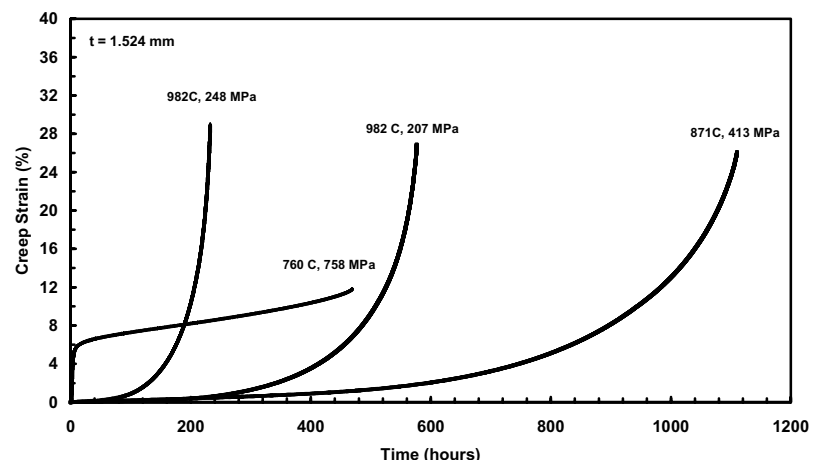

Figure 5 Typical creep curves obtained from sheet specimens $(\mathrm{t}=$ $1.52 \mathrm{~mm})$ tested at various test conditions from $760^{\circ} \mathrm{C}$ to $982^{\circ} \mathrm{C}$.

Figure 5 displays the creep curves obtained from $1.52 \mathrm{~mm}$ thick sheet specimens tested at different conditions. A comparison of these curves with those shown in Figure 4 suggests that the basic nature of the creep curves is unaffected by the specimen geometry. Figures 6 (a), (b), and (c) depict the influence of specimen thickness on the creep curves obtained at $760^{\circ} \mathrm{C} / 758 \mathrm{MPa}\left(1400^{\circ} \mathrm{F} / 110 \mathrm{ksi}\right), 871^{\circ} \mathrm{C} / 413 \mathrm{MPa}\left(1600^{\circ} \mathrm{F} / 60 \mathrm{ksi}\right)$ and $982^{\circ} \mathrm{C} / 248 \mathrm{MPa}\left(1800^{\circ} \mathrm{F} / 36 \mathrm{ksi}\right)$, respectively. It is clear that the initial portions of the creep curves are very similar. Thereafter, the curves corresponding to different thicknesses diverge continuously until rupture.

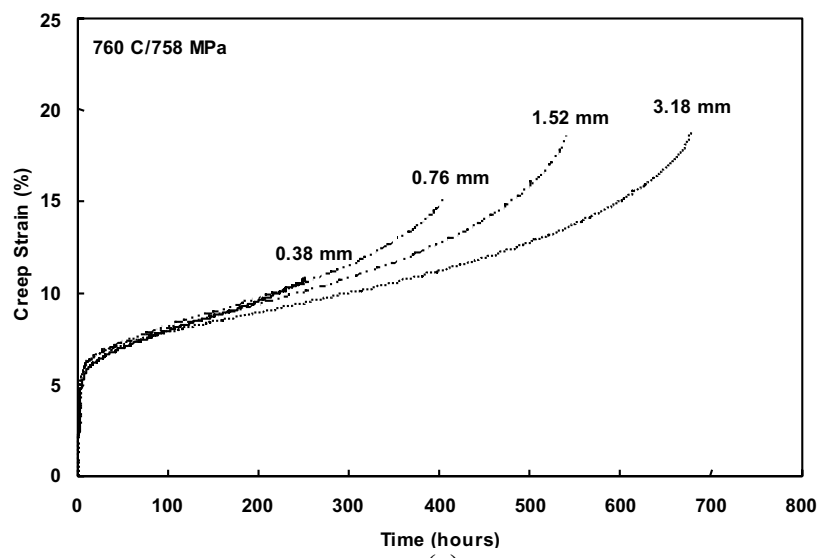

(a)

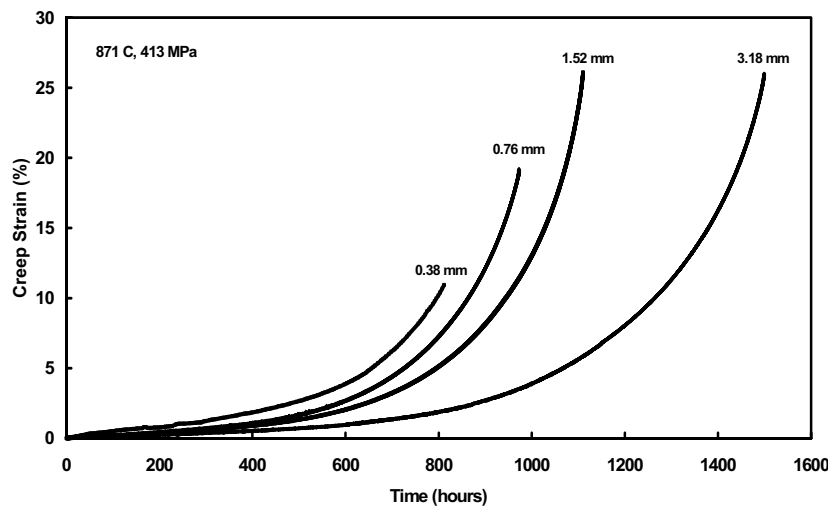

(b)

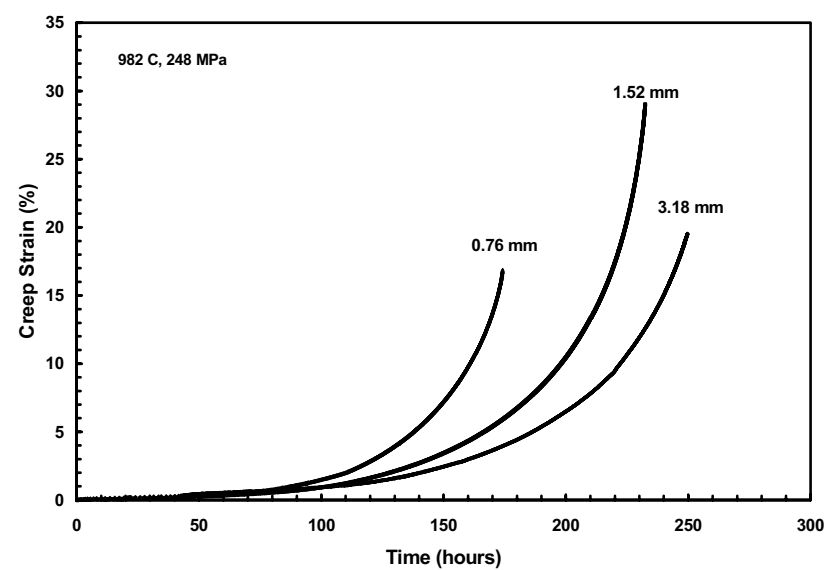

(c)

Figure 6 Effect of specimen thickness on typical creep curves from sheet specimens tested at (a) $760^{\circ} \mathrm{C} / 758 \mathrm{MPa}$, (b) $871^{\circ} \mathrm{C} / 413 \mathrm{MPa}$ and (c) $982^{\circ} \mathrm{C} / 248 \mathrm{MPa}$. 

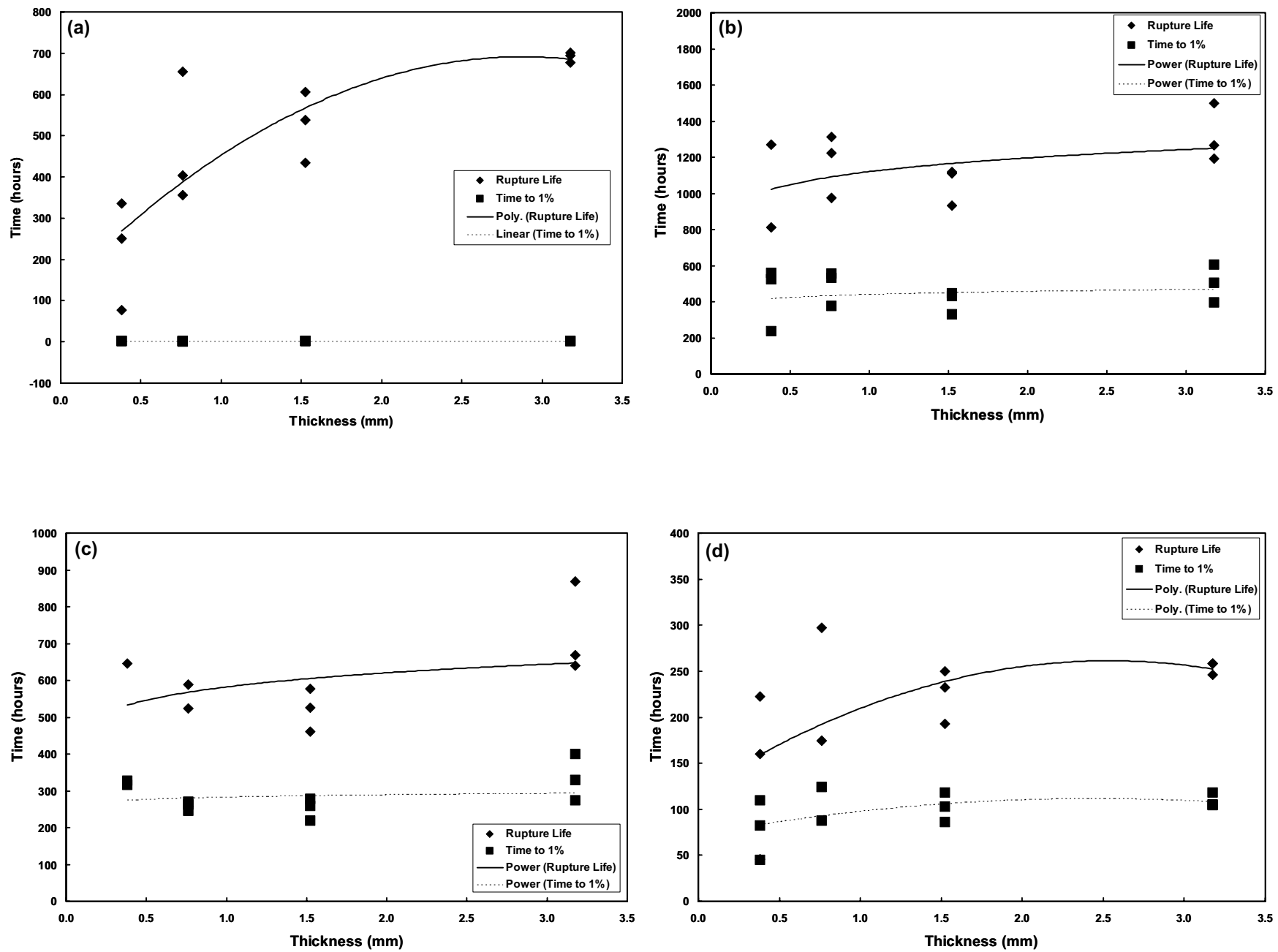

Figure 7 Effect of specimen thickness on the time for $1 \%$ creep strain and the rupture life (a) $760^{\circ} \mathrm{C} / 758 \mathrm{MPa}$, (b) $871{ }^{\circ} \mathrm{C} / 413 \mathrm{MPa}$, (c) $982^{\circ} \mathrm{C} / 207 \mathrm{MPa}$, and (d) $982^{\circ} \mathrm{C} / 248 \mathrm{MPa}$.

Figures $7(\mathrm{a})-(\mathrm{d})$ show the variation in time to reach $1 \%$ creep strain as well as rupture life as functions of the specimen thickness for different test conditions. It is important to note that the figures include data obtained from multiple tests conducted at each condition. The overall scatter in the rupture life data increased with a decrease in specimen thickness. Two important inferences can be drawn from the figures: (a) The time to $1 \%$ creep strain shows a weak dependence on specimen thickness for all test conditions and (b) the magnitude of the thickness debit on rupture life is a strong function of the test condition. For example, the influence of thickness on rupture life is fairly strong for tests conducted at $760^{\circ} \mathrm{C} / 758 \mathrm{MPa}\left(1400^{\circ} \mathrm{F} / 110 \mathrm{ksi}\right)$ and $871^{\circ} \mathrm{C} / 413 \mathrm{MPa}$ $\left(1600^{\circ} \mathrm{F} / 60 \mathrm{ksi}\right)$. The effect is weak-to-moderate for creep tests performed at $982^{\circ} \mathrm{C} / 207 \mathrm{MPa}\left(1800^{\circ} \mathrm{F} / 30 \mathrm{ksi}\right)$ and at $982^{\circ} \mathrm{C} /$ $248 \mathrm{MPa}\left(1800^{\circ} \mathrm{F} / 36 \mathrm{ksi}\right)$. These observations can be interpreted as follows:

- Specimen thickness exerts a minimal influence on the mechanisms and the kinetics of plastic deformation at small strains (until the onset of cavitation or cracking). Thereafter, the degree of plastic constraint in the ligament between cavities is strongly influenced by the specimen thickness and leads to the observed thickness debit in the rupture life.

- Rupture life at intermediate temperatures, $704^{\circ} \mathrm{C}-815^{\circ} \mathrm{C}$ $\left(1300^{\circ} \mathrm{F}-1500^{\circ} \mathrm{F}\right)$ is very sensitive to small differences in crystal orientation and microstructure. In contrast, creep deformation at high temperatures $\left(\geq 871^{\circ} \mathrm{C}\right)$ occurs by dislocation motion in multiple slip systems and is controlled by dislocation climb. Accordingly, the rupture life at high temperatures is much less sensitive to small deviations in the crystal orientation [14-18]. These differences in the fundamental deformation mechanisms may, in part, account for the observed thickness debit dependence on test temperature.

Figures 8 (a) and (b) compare the typical microstructures of the through-thickness (longitudinal) sections of specimens with thicknesses equal to $3.18 \mathrm{~mm}$ and $1.52 \mathrm{~mm}$, respectively. Both micrographs were recorded at locations close to the fracture zone. Cavities and cracks formed in the interdendritic regions and oriented normal to the loading direction are clearly discernible. Because interdendritic regions are relatively weak as a result of having slightly coarser $\gamma^{\prime}$ microstructure than the dendrite cores, they serve as preferred sites for cavity initiation. 

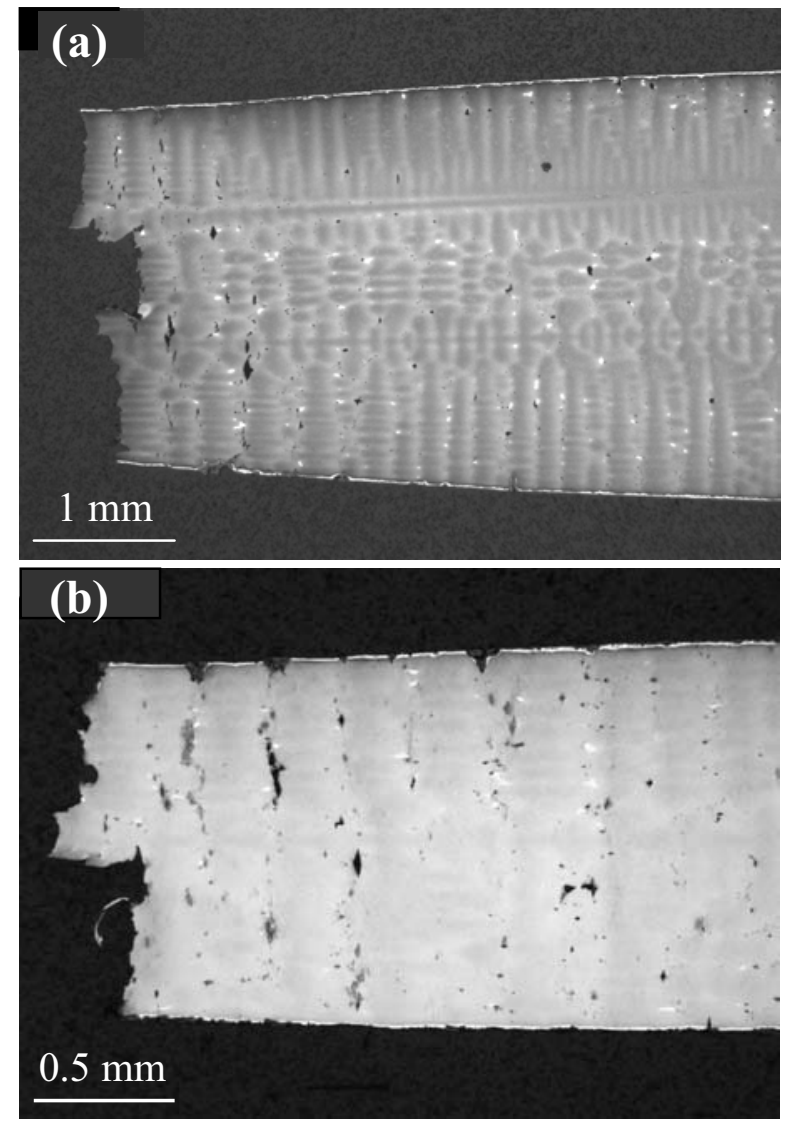

Figure 8 Longitudinal microstructures of specimens tested at $982^{\circ} \mathrm{C} / 248 \mathrm{MPa}$ (Loading direction is horizontal) (a) $\mathrm{t}=3.18 \mathrm{~mm}$ and (b) $\mathrm{t}=1.52 \mathrm{~mm}$.

Fracture surfaces obtained at low temperatures contain numerous crystallographic facets indicative of planar, inhomogeneous plastic deformation. Because the deformation process becomes much more homogeneous at high test temperatures, the crystallographic facets become less pronounced (Figure 9). The fracture morphology shown in Figure 9 is found to be typical and independent of specimen thickness or geometry.

Figure 10 compares the microstructures of the shoulder region (strain $\approx 0 \%$ ) and the fracture zone (strain $\approx 36 \%$ ) from a specimen creep tested at $982^{\circ} \mathrm{C} / 248 \mathrm{MPa}\left(1800^{\circ} \mathrm{F} / 36 \mathrm{ksi}\right)$. It is

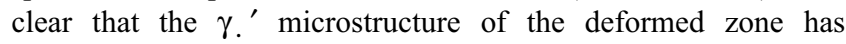
undergone extensive rafting in the direction normal to the tensile axis. This finding is consistent with other observations on superalloys characterized by a small negative misfit between the lattices of $\gamma$ and $\gamma^{\prime}$. Because of long thermal exposure at $982^{\circ} \mathrm{C}$ $\left(1800^{\circ} \mathrm{F}\right)$, the $\gamma^{\prime}$ precipitates in the shoulder zone have coarsened substantially (average size of primary, blocky $\gamma^{\prime} \sim 0.7 \mu \mathrm{m}$ ), without any concomitant change in the precipitate morphology. Neither rafting nor coarsening of $\gamma^{\prime}$ was detected in specimens tested at $760^{\circ} \mathrm{C}$ or $871^{\circ} \mathrm{C}$.
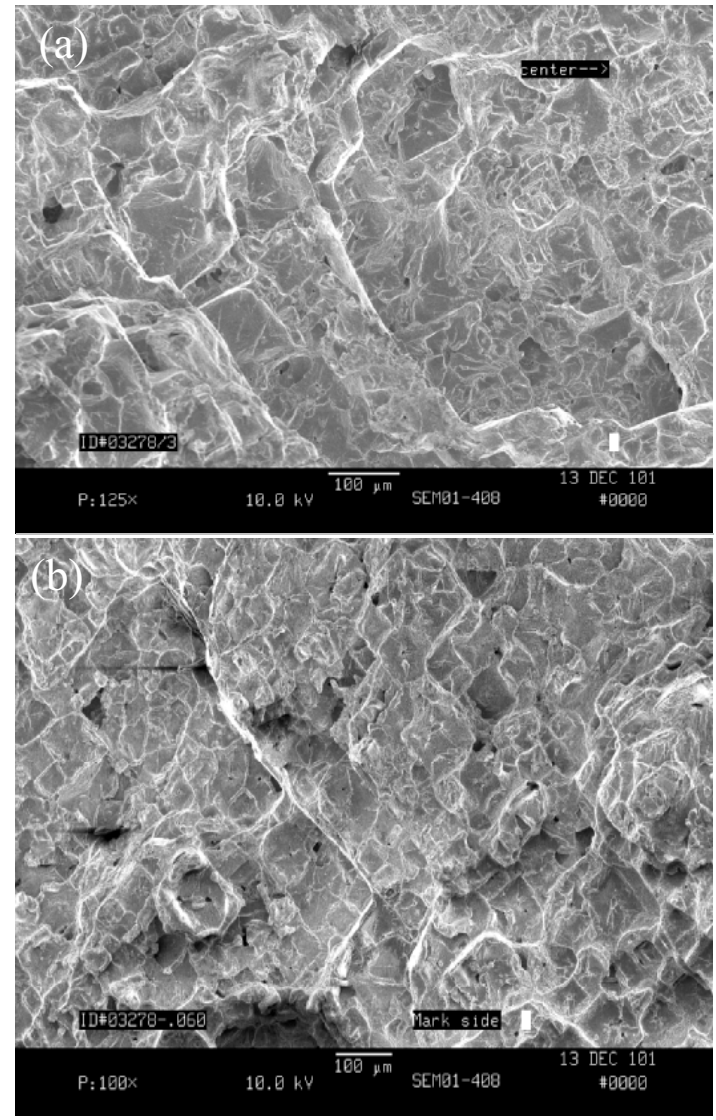

Figure 9 Fracture morphologies of specimens with $\Phi=3.18 \mathrm{~mm}$ and $\mathrm{t}=1.52 \mathrm{~mm}$ tested at $982^{\circ} \mathrm{C} / 248 \mathrm{MPa}\left(1800^{\circ} \mathrm{F} / 36\right.$ ksi).

\section{Discussion}

Figures 11 (a) and (b) summarize the salient results of the current work in the form of the effect of specimen thickness on the average time to $1 \%$ strain and the average rupture life, respectively. Since the effect of section thickness on time to $1 \%$ strain is minimal, it requires no further discussion. The thickness debit on rupture life can be understood better if the data are normalized with respect to the rupture lives of the bulk material. Figure 12 illustrates the variation in the normalized rupture life for different test conditions. The maximum value of the thickness debit $(\sim 60 \%)$ is observed at $760^{\circ} \mathrm{C} / 758 \mathrm{MPa}\left(1400^{\circ} \mathrm{F} / 110 \mathrm{ksi}\right)$. In contrast, the rupture lives at $871^{\circ} \mathrm{C}$ and $982^{\circ} \mathrm{C}\left(1600^{\circ} \mathrm{F}\right.$ and $1800^{\circ} \mathrm{F}$ ) exhibit a modest dependence on specimen thickness.

While the information shown in Figure 12 is very useful from a scientific viewpoint, it cannot be used directly in the design of airfoils. Instead, it is necessary to plot the thickness debit in terms of rupture strength rather than rupture life. The relationship between the debits on rupture strength and rupture life can be understood with the aid of the schematic diagram shown in Figure 13. At any given temperature and stress, the debit in rupture life can be represented in terms of the horizontal displacements 
between the Larson-Miller plots for the 'thick' and 'thin' sections. Similarly, the vertical displacement between the two plots at a fixed time or rupture life denotes the change in the creep or rupture strength of the alloy with section thickness, i.e., thickness debit on creep strength.

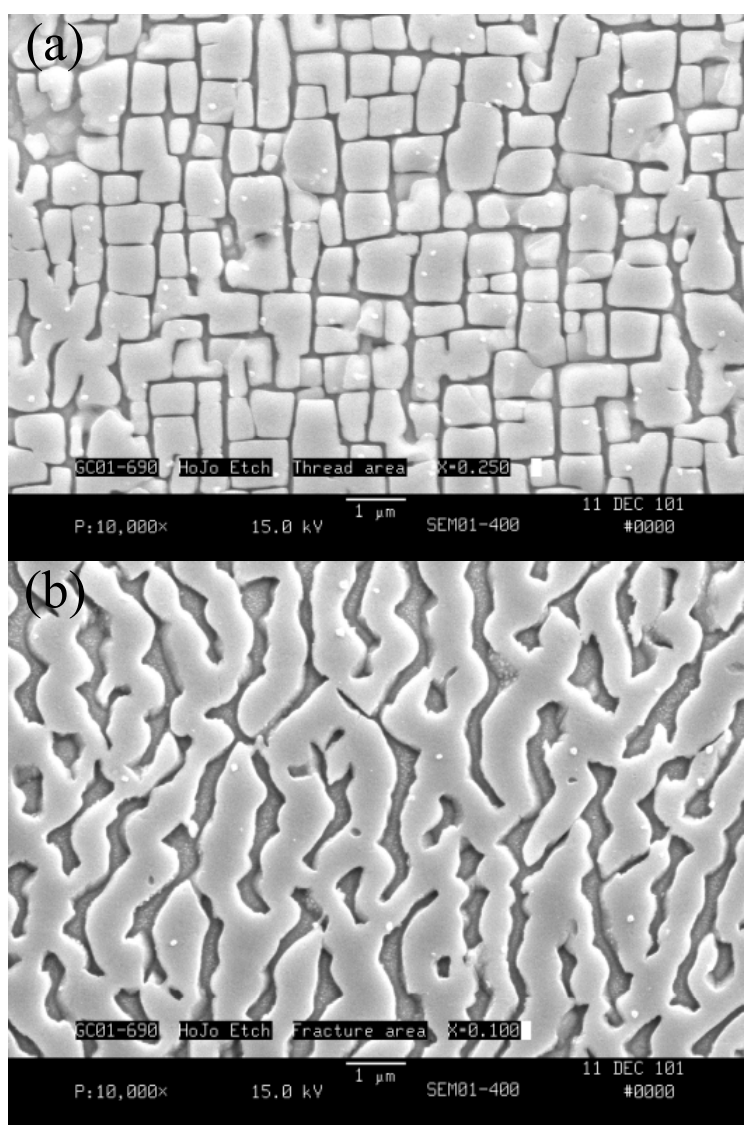

Figure 10 Microstructures of the (a) shoulder and (b) fracture zones from the specimen tested at $982^{\circ} \mathrm{C} / 248 \mathrm{MPa}$ (Loading direction is horizontal). Note extensive rafting in (b).

Isothermal creep rupture data (stress, $\sigma$ vs. rupture time, $\mathrm{t}_{\mathrm{r}}$ ) were analyzed in terms of the following power-law type equation:

$$
\sigma=\mathrm{Kt}_{\mathrm{r}}^{-\mathrm{n}}
$$

The value of the exponent, $\mathrm{n}$ increases from about 0.05 to 0.17 as the temperature increases from $760^{\circ} \mathrm{C}$ to $982^{\circ} \mathrm{C}$. Using the slopes of the isothermal stress vs. rupture life plots, one can construct the effect of section thickness on the rupture strength. The thickness debit associated with the (normalized) rupture strength of PWA 1484 is illustrated in Figure 14. The effect of thickness on the rupture strength was found to be minimal $(<10 \%)$ at all test conditions. This finding can be rationalized in terms of the variation in the slope, $\mathrm{n}$ of the life vs. stress plots with temperature for isothermal creep rupture tests. For example, a large debit in rupture life observed at $760^{\circ} \mathrm{C} / 758 \mathrm{MPa}\left(1400^{\circ} \mathrm{F} / 110 \mathrm{ksi}\right)$ translates into a relatively small debit in rupture strength because of the low value of the slope, $\mathrm{n}=0.06$. Even though the debit in the rupture life of specimens tested at $871^{\circ} \mathrm{C}$ and $982^{\circ} \mathrm{C}\left(1600^{\circ} \mathrm{F}\right.$ and $\left.1800^{\circ} \mathrm{F}\right)$ is relatively small, the higher $\mathrm{n}$ value $(0.14-0.17)$ pertaining to these temperatures leads to a debit in rupture strength of the order of $5 \%$.
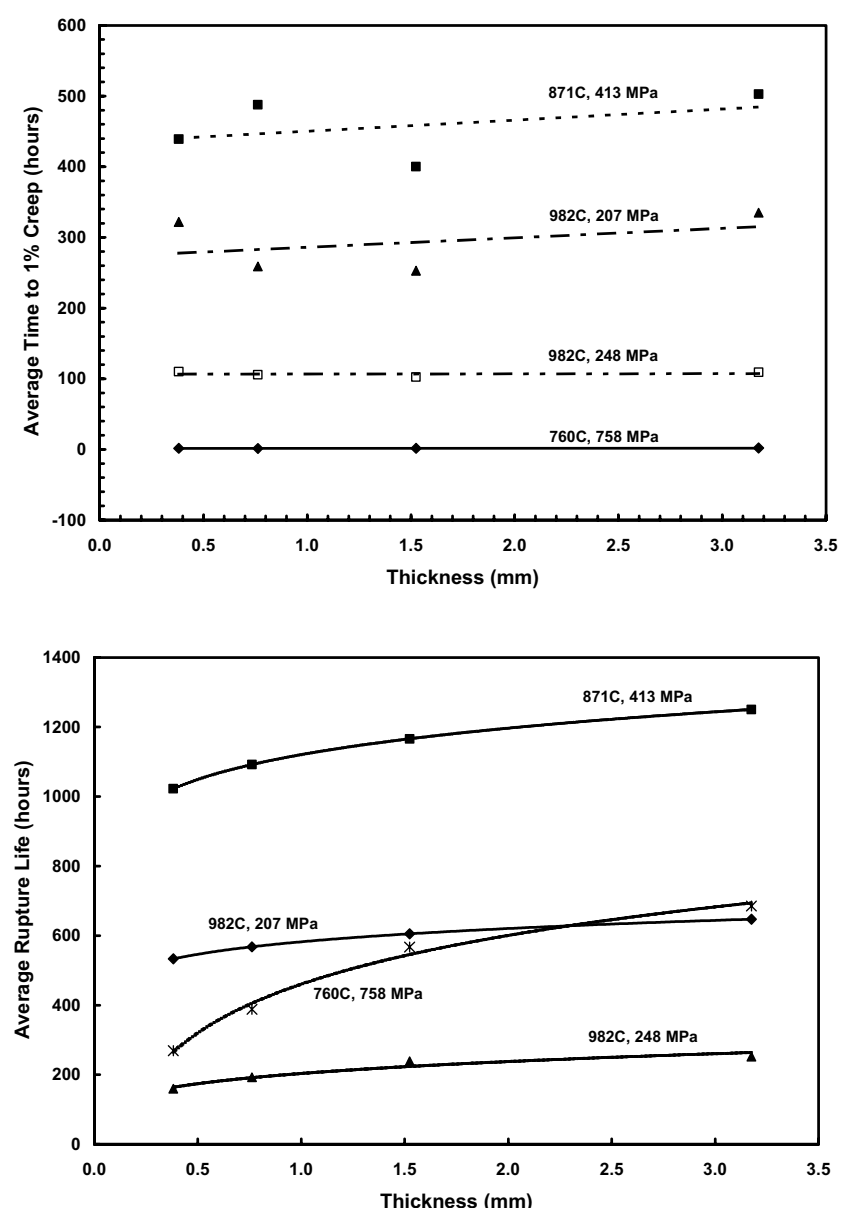

Figure 11 Effect of specimen thickness on (a) the average time to attain $1 \%$ creep strain and (b) average rupture life at test temperatures varying from $760^{\circ} \mathrm{C}$ to $982^{\circ} \mathrm{C}$.

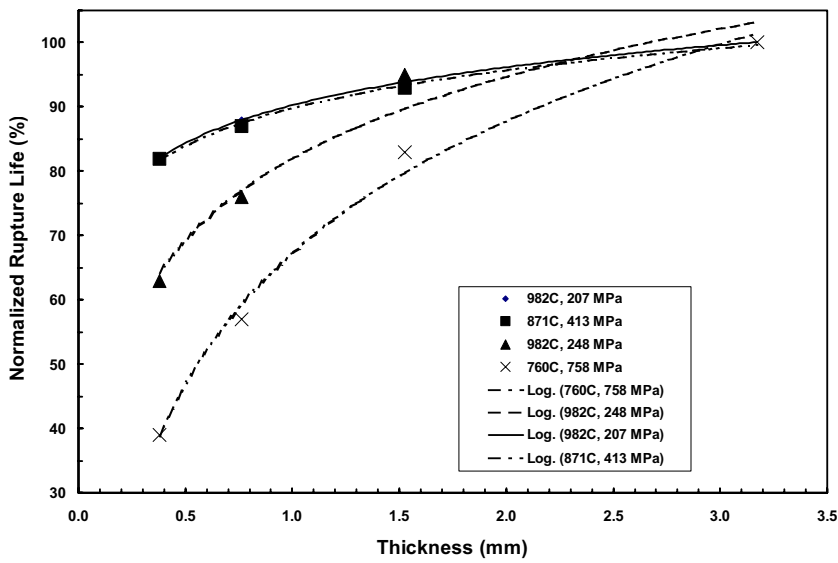

Figure 12 Normalized rupture life (percent of thick section life) $v s$. specimen thickness for test data generated for temperatures varying from $760^{\circ} \mathrm{C}$ to $982^{\circ} \mathrm{C}$. 


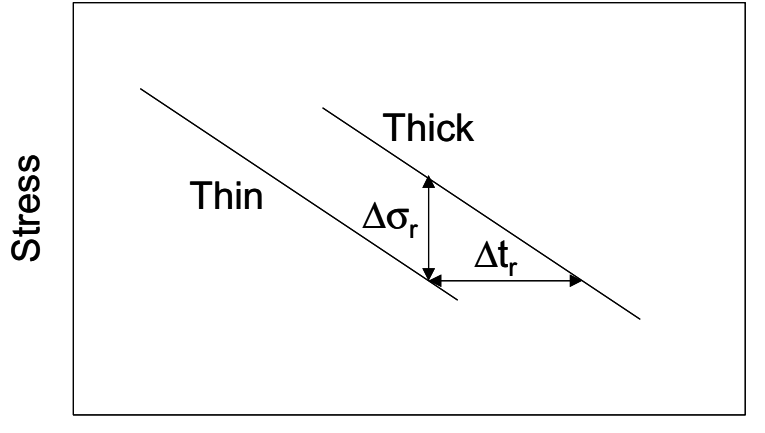

L-M Parameter $\{(\mathrm{C}+\log \mathrm{t})(\mathrm{T}+273)\}$

Figure 13 Schematic diagram showing the relationship between the debit in rupture life and the debit in creep rupture strength.

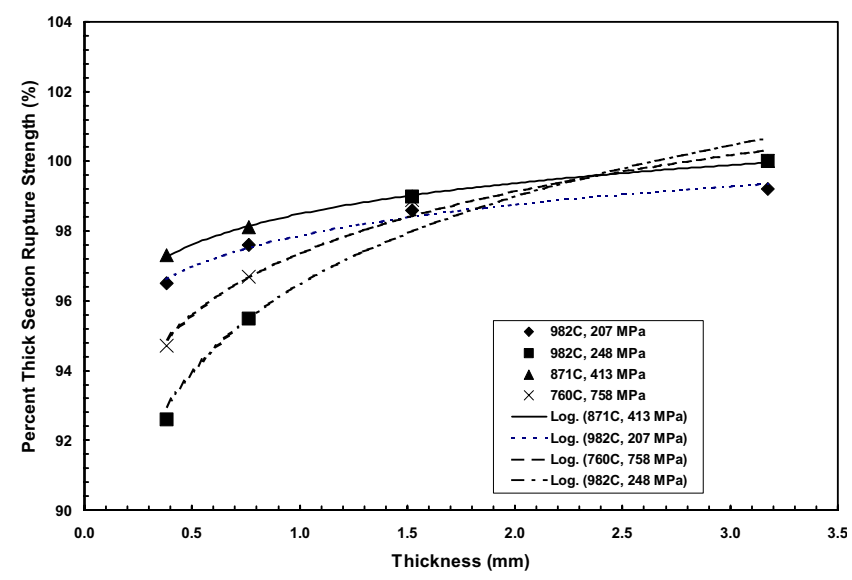

Figure 14 Normalized thickness debit on the rupture strength of PWA 1484 based on creep test data generated for temperatures varying from $760^{\circ} \mathrm{C}$ to $982^{\circ} \mathrm{C}$.

\section{Summary and Conclusions}

Isothermal, constant load creep tests were performed on $<100>$ oriented, flat, and uncoated specimens of PWA 1484 in order to study the influence of section thickness on creep properties. Analysis of the creep test data led to the following major conclusions:

(1) Time to $1 \%$ creep strain was found to be weakly dependent on the specimen thickness for all test conditions.

(2) The thickness debit on the creep rupture life was highest $(\sim 60 \%)$ at low temperatures and high stresses $\left(760^{\circ} \mathrm{C} / 758 \mathrm{MPa}\right)$. In contrast, rupture lives at $871^{\circ} \mathrm{C}$ and $982^{\circ} \mathrm{C}$ exhibited a relatively modest dependence on specimen thickness.

(3) When the creep data were analyzed in terms of thickness debit on creep strength, the effect of thickness on rupture strength was found to be minimal $(<10 \%)$ at all test conditions. This finding can be rationalized in terms of the variation in the slope of the life vs. stress plots with temperature for isothermal creep rupture tests.

(4) The influence of specimen thickness on rupture life can be interpreted in terms of the effect of plastic constraint on the deformation and fracture of ligaments between the interdendritic voids formed during creep deformation.

\section{Acknowledgments}

This work was conducted as part of the in-house R\&D activities of Pratt \& Whitney, United Technologies Corporation. The support of the work by R. K. Agrawal is gratefully acknowledged. The authors wish to thank Dr. S. Bose for his continuous encouragement and support for this work.

\section{References}

1. D. N. Duhl: "Directionally Solidified Superalloys", in Superalloys II, C.T. Sims, N. S. Stoloff, and W. C. Hagel, (Eds.) John Wiley, New York, NY, pp. 189-214 (1987).

2. H.E. Collins and L.D. Graham: Technical Report TR72-28, Wright-Patterson Air Force Base, OH (1972).

3. E.G. Richards: J. Inst. Metals, Vol. 96, 365 (1968).

4. T.B. Gibbons: Metals Technology, Vol. 8, 472 (1981).

5. M. Gell and D. N. Duhl: Processing and Properties of Advanced High Temperature Alloys, S. Allen, et al. (Eds.), ASM, Metals Park, OH, 41 (1986).

6. D. N. Duhl: "Single Crystal Superalloys" in Superalloys, Supercomposites, and Superceramics, J.K. Tien and T. Caulfield (Eds.), Academic Press, Inc. New York, NY, pp. 149-182 (1989).

7. M.R. Winstone and J.E. Northwood: "Structure and Properties of Directionally Solidified Superalloys in Thin sections", in Solidification Technology in the Foundry and Cast House, The Metals Society, London, U.K., pp.298-303 (1980).

8. D. A. Woodford: "Accelerated High Temperature Performance Evaluation for Alloy Optimization, Embrittlement, and Life Assessment", Unpublished research (2002).

9. M. Doner and J.A. Heckler: "Effects of Section Thickness and Orientation on Creep-Rupture properties of Two Advanced Single Crystal Alloys", in SAE Technical Paper \# 851785, Society of Automotive 
Engineers, Inc. (1985).

10. M. Doner and J.A. Heckler: "Identification of Mechanisms responsible for Degradation in Thin-wall Stress Rupture Properties", Superalloys 1988, Proceedings of the $6^{\text {th }}$ International Symposium on Superalloys, The Metallurgical Society, Warrendale, PA, pp.653-662, 1988.

11. F.O. Soechting: Pratt \& Whitney, East Hartford, CT, Unpublished work, 1982.

12. D. N. Duhl and A.D. Cetel: "Advanced High Strength Single Crystal Superalloy Compositions", U.S. Patent 4719080, January 12, 1988.

13. A.D. Cetel and D. N. Duhl: "Second Generation NickelBase Single Crystal Superalloy", Superalloys 1988, Proceedings of the $6^{\text {th }}$ International Symposium on Superalloys, The Metallurgical Society, Warrendale, PA, pp.235-244, 1988.

14. R. N. Ghosh, R.V. Curtis, and M. McLean: "Creep Deformation of Single Crystal Superalloys - Modeling the Crystallographic Anisotropy", Acta Met. Mater., Vol. 38, 1977 (1990).

15. L.-M. Pan, B.A. Shollock, and M. McLean: "Modeling of the High Temperature Mechanical Behavior of a Single-Crystal Superalloy", Proc. Royal Soc. London A, Vol. 453, pp. 1689-1715 (1997).

16. C.M.F. Rae, N. Matan, D.C. Cox, M.A. Rist, and R.C. Reed: "On the Primary Creep of CMSX-4 Superalloy Single Crystal", Metall. Mater. Trans. A, Vol. 31A, pp. 2219-2228 (2000).

17. D. W. MacLachlan, L.W. Wright, S.S.K. Gunturi, and D.M. Knowles: "Modeling the Anisotropic and Biaxial Creep Behavior of Ni-Base Single Crystal Superalloys CMSX-4 and SRR99 at 1223 K", Superalloys 2000, Eds. T. M. Pollock, et al., TMS, Warrendale, PA, pp. 357-366 (2000).

18. D. W. MacLachlan and D.M. Knowles: "Creep Behavior Modeling of the Single-Crystal Superalloy CMSX-4", Metall. Mater. Trans. A, Vol. 31A, pp. 1401$1411(2000)$. 